\title{
A escola como instituição de controle?! Uma análise de memórias educativas
}

\author{
The school as an institution of control?! An analysis of educational memories \\ ¿La escuela como institución de control?Análisis de memorias educativas
}

Recebido: 27/09/2021 | Revisado: 05/10/2021 | Aceito: 12/10/2021 | Publicado: 12/10/2021

\author{
Maria Gabriella Guimaraes da Silva \\ ORCID: https://orcid.org/0000-0002-0083-0691 \\ Universidade Federal do Rio Grande do Norte, Brasil \\ E-mail: guimaraesmariagabriela@gmail.com \\ Olívia Morais de Medeiros Neta \\ ORCID: https://orcid.org/0000-0002-4217-2914 \\ Universidade Federal do Rio Grande do Norte, Brasil \\ E-mail: olivianeta@gmail.com
}

\begin{abstract}
Resumo
O presente trabalho aborda a escola como uma instituição de controle, nas últimas décadas, a partir da análise de memórias educativas produzidas durante o "Projeto Suplementar de Ensino: História e Historiografia da Educação no Rio Grande do Norte", realizado pela Universidade Federal do Rio Grande do Norte, no semestre suplementar de 2020.5. Com o objetivo de analisar os materiais coletados, atentando aos dispositivos de controle, encontrados nas memórias dos participantes. Metodologicamente, os relatos presentes nos memoriais, foram selecionados e catalogados, partindo de tópicos e subtópicos de análise, usando da análise temática, como forma de análise. Teoricamente, Michel Foucault corroborou com o entendimento de dispositivos de controle e sociedade disciplinar, em especial, e Le Goff com a concepção de memória. Tendo como resultados a catalogação de cerca de setenta e cinco memoriais educativos, dentro de temas de análises, partindo assim para a conclusão em que a pesquisa apontou para a importância das memórias como um elemento formativo e de como são evidentes os dispositivos de controle dentro das memórias educativas analisadas.
\end{abstract}

Palavras-chave: Instituição de controle; Memórias; Memoriais.

\begin{abstract}
The present work approaches the school as a control institution, in the last decades, from the analysis of educational memories produced during the "Supplementary Teaching Project: History and Historiography of Education in Rio Grande do Norte", carried out by the Federal University of Rio Grande do Norte, in the supplementary semester of 200.5. In order to analyze the collected materials, paying attention to the control devices found in the participants' memories. Methodologically, the reports present in the memorials were selected and cataloged, starting from topics and subtopics of analysis, using thematic analysis as a form of analysis. Theoretically, Michel Foucault corroborated with the understanding of control devices and disciplinary society, in particular, and Le Goff with the conception of memory. The results were the cataloging of about seventy-five educational memorials, within the themes of analysis, thus proceeding to the conclusion that the research pointed to the importance of memories as a formative element and how the control devices within the analyzed educational memories.
\end{abstract}

Keywords: Control institution; Memoirs; Memorials.

\section{Resumen}

El presente trabajo aborda la escuela como institución de control, en las últimas décadas, a partir del análisis de las memorias educativas producidas durante el "Proyecto Docencia Suplementaria: Historia e Historiografía de la Educación en Rio Grande do Norte", realizado por la Universidad Federal de Rio. Grande do Norte, en el semestre suplementario de 2020.5. Para analizar los materiales recolectados, prestando atención a los dispositivos de control que se encuentran en la memoria de los participantes. Metodológicamente, los informes presentes en los memoriales fueron seleccionados y catalogados, a partir de temas y subtemas de análisis, utilizando el análisis temático como forma de análisis. Teóricamente, Michel Foucault corroboró con la comprensión de los dispositivos de control y la sociedad disciplinaria, en particular, y Le Goff con la concepción de la memoria. Los resultados fueron la catalogación de alrededor de setenta y cinco memoriales educativos, dentro de los temas de análisis, procediendo así a la conclusión de que la investigación apuntó a la importancia de los recuerdos como elemento formativo y cómo los dispositivos de control dentro de las memorias educativas analizadas.

Palabras clave: Institución de control; Memorias; Memoriales. 


\section{Introdução}

A escola se constituiu historicamente, na sociedade ociental, como um espaço formativo no qual os seres humanos passam boa parte de suas vidas dentro delas. A exemplo, é dentro de escolas que se aprende os mais variados tipos de conteúdos e se conhece a mais vasta diversidade cultural, na maioria dos casos. Esses anos vividos dentro desta instituição são essenciais para a construção do ser social, que constitui o ser humano, ao crescer apesar de não ser a única instituição social que tem influência na trajetória de vida das pessoas. Ela exerce um grande papel na construção dos pensamentos, opiniões e pontos de vista durante o desenvolvimento crítico e social. ${ }^{1}$

Sejam elas positivas ou negativas, todos os que passaram pela instituição escolar carregam memórias referentes à escola durante a vida. Seja apenas uma repreensão de uma professora, os amigos que foram feitos na época, ou até mesmo um conteúdo que lhe fez seguir um determinado caminho acadêmico. Tudo isso são momentos vividos dentro da escola que são carregados, com o decorrer da vida. À vista disto, podemos observar que a escola deixa marcas em forma de memórias, nos mais variados graus em seus alunos.

Essas memórias escolares trazidas ao longo da vida são imprescindíveis para a constituição dos pensamentos e ideais do indivíduo. Muitas vezes as recordações estão atreladas aos dispositivos de controle usados pela escola no seu cotidiano, neutralizados como costumes escolares, que deveriam ser feitos por todos. Desta forma, o presente trabalho tem como objetivo a discussão e a análise de como, a escola se utiliza dos dispositivos de controle dentro das memórias relatadas pelos participantes do projeto. Para tal, far-se-á a análise de memórias produzidas no contexto do "Projeto Suplementar de Ensino: História e Historiografia da Educação no Rio Grande do Norte". ${ }^{2}$

O referido projeto foi realizado pela Universidade Federal do Rio Grande do Norte, durante o período de ensino suplementar de 2020.5. ${ }^{3}$ Durante uma atividade de finalização do projeto, intitulada "Minhas Memórias Educativas", que consistiu em um relato escrito, foi produzido pelos alunos textos memoriais sobre suas trajetórias escolares; com o objetivo dos alunos desenvolverem uma reflexão sobre suas situações vividas em sua trajetória escolar, desde a educação infantil até a graduação. Sobre o uso de memoriais escolares concordamos com Chacon et al (2020) quando exprimem que o usos destes trazem a necessidade de nos distanciarmos das compreensões dominantes nos contextos escolares, seja sobre a avaliação da aprendizagem como algo limitado a uma dimensão somativa ou mesmo sobre o cotidiano na escola. Assim, ressaltamos que os memoriais exprimem narrativas autobiográficas como prática pedagógica, com vistas à experiência. (Passeggi, 2011).

Com base nas análises destas memórias, analisou-se situações reais vividas por alunos que receberam ao longo da vida os mais diversos métodos de ensino e que conviveram nas mais variadas épocas de contextos escolares. Utilizando-se de experiências reais de vivências escolares, produzidas por esses alunos, esta pesquisa se valeu dos conceitos apresentados por Michel Foucault (1987; 2003), relacionado aos pensamentos e conceitos sobre os dispositivos de controle trazidos pelo autor, nos seus escritos.

No livro Vigiar e Punir, Foucault traz o seguinte pensamento: "O que há de surpreendente se a prisão se assemelha às fábricas, às escolas, às casernas, aos hospitais, que todos se pareçam com a prisão?” (Foucault, 1987, p. 229). Perante esta perspectiva, a escola se encontra no mesmo patamar de uma prisão, quando se relaciona com os dispositivos de controle. As duas instituições possuem o mesmo desígnio de controlar os corpos de quem ingressar nessas instituições.

\footnotetext{
${ }^{1}$ Sendo dividida em etapas a escola como conhecemos atualmente, surgiu na Idade Média, com o propósito de preparar para a nova sociedade capitalista e cheia de processos mais técnicos. Assim, atualmente uma pessoa permanece cerca de 15 anos na escola, contando apenas o ensino básico.

${ }^{2}$ As aulas do projeto estão acessíveis pelo portal do LAHMED no YouTube: www.youtube.com/lahmedufrn

${ }^{3}$ Período letivo suplementar excepcional, organizado pela UFRN, com o intuito de oferecer componentes curriculares e outras atividades educacionais em formato remoto. Em função da suspensão das aulas e atividades presenciais, seguindo as orientações da Resolução ${ }^{\circ}$ 023/2020-CONSEPE, de 01 de junho de 2020.
} 
Para exercer esse controle, o autor traz alguns dos dispositivos que são usados na busca pelos corpos disciplinados, sendo eles: "O olhar hierárquico, a sanção normalizadora e sua combinação num procedimento que lhe é específico, o exame" (Foucault, 1987, p. 219). Serão a partir desses outros dispositivos de controle que se deu a partida deste trabalho, posto que se utiliza daqueles dispositivos postos por Michel Foucault para relacionar as memórias educativas, que serão analisadas.

Nas instituições escolares, os dispositivos de controle estão diluídos em seus projetos pedagógicos, ações e até leis assim criadas com uma ótica que os afetam diretamente. Ou seja, são dispositivos que afetam diretamente as pessoas que recebem o conhecimento e as informações que estão dentro delas. A escola possui um papel de extrema grandeza na sociedade para não ser utilizada de uma forma consciente. Assim, fica o questionamento que trouxe a fazer este trabalho ser escrito: Como as memórias educativas dos participantes do projeto de ensino, revelam os elementos constituintes dos dispositivos de controle citados por Foucault?

\section{Metodologia}

Esta pesquisa, metodologicamente, parte de uma análise temática trazida por Minayo (1992), no livro Desafio do conhecimento. Para a autora, este tipo de análise como "A noção de tema está ligada a uma afirmação a respeito de determinado assunto. Ela comporta um feixe de relações e pode ser graficamente apresentada através de uma palavra, uma frase, um resumo." (Minayo, 1992, p. 208). Ou seja, um determinado tema pode se subdividir em vários outros, subtemas para facilitar o processo de análise.

Essa análise é feita em três etapas. A primeira é denominada pré-análise e consiste, basicamente, na organização dos materiais e definição dos temas a serem trabalhados, que ocorrem a partir da escolha dos memoriais e definição do tema. A segunda etapa, sendo a exploração, consiste de maneira geral na leitura, decodificação e na catalogação desse material escolhido. Já a terceira etapa, é onde se encontra o tratamento dos resultados obtidos e interpretação, em que o autor traz suas análises e interpretações sobre o tema que foi pesquisado.

O corpus documental da pesquisa foi o conjunto de textos memoriais produzidos no "Projeto Suplementar de Ensino: História e Historiografia da Educação no Rio Grande do Norte". Este corpus serviu de subsídio para análise de situações problemas, em que os dispositivos de controle nas vivências escolares.

Portanto, este trabalho realizou a análise de memoriais educacionais, produzidos por alunos do Curso de Pedagogia da UFRN, especificamente, daqueles que participaram do Projeto Suplementar de Ensino História e Historiografia da Educação no Rio Grande do Norte, com vistas a identificar os dispositivos de controles, apresentados pelo autor Michel Foucault. Utilizando-se da leitura de arquivos como livros, artigos, teses e dissertações já produzidas relacionando a escola e os dispositivos de controle. Desta forma garante se um aporte teórico para as ideias que serão apresentadas.

O "Projeto Suplementar de Ensino: História e Historiografia da Educação no Rio Grande do Norte", surgiu a partir do contexto de pandemia ${ }^{4}$ que se instalou pelo mundo no ano de 2020. Visto o contexto de crise sanitária em que se encontrava naquele momento, as aulas da Universidade Federal do Rio Grande do Norte foram suspensas e como uma forma de correr contra o tempo perdido, foi criado o semestre remoto denominado 2020.5. Foi nesse semestre que surgiram os projetos suplementares com o objetivo de possibilitar outras formas de aprendizagem para aqueles alunos que não conseguiram matrículas em 2020.6.

E foi neste contexto em que o projeto foi desenvolvido, contando com a coordenação das professoras Olívia Morais de Medeiros Neta e Rita Diana de Freitas Gurgel e vinculado ao Laboratório de História e Memória da Educação (LAHMED), que possui a função de organização de ações como esta na área dos "Fundamentos da Educação". Desta maneira, conforme seu

\footnotetext{
${ }^{4}$ Nome dado à disseminação de escala mundial de alguma nova doença. Está em questão está relacionada a pandemia causada pelo COVID19, no ano de 2020.
} 
programa, o projeto se apresentava com um objetivo de:

Discutir sobre a história e a historiografia da educação e possibilidades de pesquisa em história da educação no Rio Grande do Norte. Discorrer sobre acervos e fontes à pesquisa em história da educação. Debater sobre temas e abordagens de investigação em história da educação. (Lahmed, 2020).

O programa se organizou em 4 encontros síncronos via Google Meet ${ }^{5}$, nos dias 25 e 30 de junho e $1^{\circ}$ e 2 de julho de 2020. Cada encontro consistia em um tema diferente. Sendo eles: a) História e historiografia da educação no Rio Grande do Norte; b) Acervos e fontes para pesquisa em história da educação no Rio Grande do Norte; c) Temas e abordagens de investigação em história da educação no Rio Grande do Norte: intelectuais da educação e d) Temas e abordagens de investigação em história da educação no Rio Grande do Norte: educação profissional. Seguindo a programação descrita na Figura 1, apresentada logo abaixo:

Figura 1: Card de divulgação do Projeto Suplementar de Ensino: História e Historiografia da Educação no Rio Grande do Norte

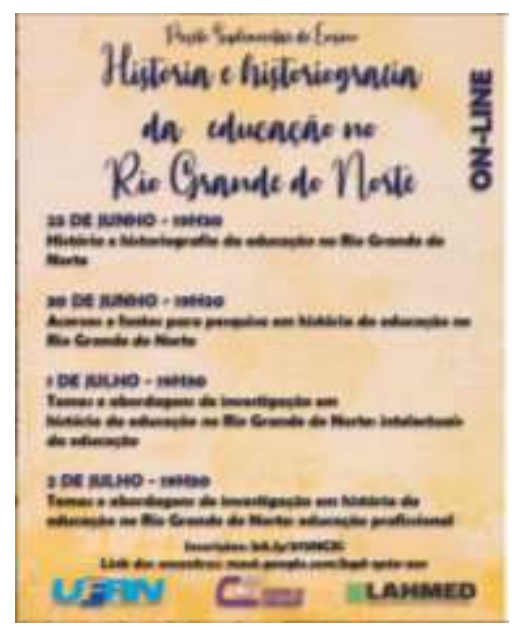

Fonte: Instagram @lahmedufrn

A atividade final proposta no âmbito do Projeto Suplementar de Ensino: História e Historiografia da Educação no Rio Grande do Norte foi a escrita de um memorial escolar. Este memorial, deveria ser produzido por todos os participantes do projeto, com o objetivo que houvesse uma reflexão sobre suas situações vividas desde os anos iniciais de suas vidas escolares. No memorial, os alunos deveriam tecer críticas às práticas que eram feitas e as situações que foram experienciadas em suas escolas, bem como com o propósito de trazer uma consideração para as suas memórias e sua história para o olhar pedagógico dos alunos.

Assim, foi através destes memoriais construídos pelos alunos que se deu o início de uma análise. Para tanto, foram analisados, com fins de caracterização dos autores, o total de 75 (setenta e cinco) memoriais. Esse total corresponde ao universo de todos os memoriais submetidos como atividade final para conclusão do Projeto Suplementar de Ensino: História e Historiografia da Educação no Rio Grande do Norte. No Quadro 1 é possível observar os elementos que constam na análise desta fase.

\footnotetext{
${ }^{5}$ Serviço de videochamadas do google, que permite que um grupo de pessoas façam reuniões onlines, bastante utilizado durante o período de aulas remotas devido a pandemia do covid-19.
} 
Quadro 1: Caracterização dos autores dos memoriais.

\begin{tabular}{|c|c|c|c|c|}
\hline NOME & HOMEM/MULHER & $\begin{array}{c}\text { NASCIMENTO: } \\
\text { ANTES OU DEPOIS } \\
\text { DOS ANOS 2000 }\end{array}$ & $\begin{array}{c}\text { REDE PÚBLICA OU } \\
\text { PARTICULAR }\end{array}$ & $\begin{array}{c}\text { RURAL OU } \\
\text { URBANO }\end{array}$ \\
\hline Memorial 1 & $\mathrm{H}$ & Antes & Pública & Rural \\
\hline Memorial 2 & $\mathrm{M}$ & Depois & Privada & Urbana \\
\hline
\end{tabular}

Fonte: Autores.

Sendo os quatros critérios: o sexo dos participantes, se passaram a maior parte dos seus anos escolares em escolas da rede particulare ou na rede pública de ensino. Foram divididos também entre suas idades, sendo separados entre os que nasceram antes e os que nasceram depois dos anos 2000. E por último, os participantes foram divididos entre aqueles que tiveram sua escolarização nos centros urbanos ou em áreas rurais.

Para uma melhor organização desses critérios foram divididos em grupos, para que a descrição dos participantes pudesse ser feita ao longo do texto. Desta forma, o primeiro criterio relacionado ao sexo foi dividido da seguinte forma: GRUPO M, para os participantes do sexo femininos e GRUPO H para os participantes do sexo masculino. Já a distinção das escolas se dividiu em GRUPO RPA, para aqueles que estudaram em escola particular e GRUPO RPU para os que estudaram em escola pública. Para separar o terceiro critério, relacionado ao nascimento, pode-se entender que o GRUPO A, está nascidos antes dos anos 2000 e o GRUPO D, para aqueles que nasceram depois dos anos 2000. O último critério foi dividido nos GRUPO U, para os que estudaram em zonas urbanas e no GRUPO R, para os que estudaram em áreas rurais.

O processo de separação e análise foi feito através da ferramenta de trabalho online, denominada Google documentos (disponível gratuitamente na internet) e Google planilhas. Os documentos foram organizados em tabelas onde continham o nome e todos os critérios já citados anteriormente, que iam sendo marcados a cada término de leitura de um memorial diferente.

Posterior a leitura dos memoriais para caracterização dos autores, foram catalogados recortes de lembranças principais em categorias, a saber: disciplina, castigo, avaliação/exame, espaço ${ }^{6}$ escolar e tempo. Optamos por constituir as categorias a partir dos apontamentos presentes nas discussões teóricas apresentadas por Foucault (1987; 2003). Ver Figura 2.

${ }^{6}$ Para mais informações sobre o conceito de espaço, ver Certeau (2014). 
Figura 2: Infográfico da categorização dos memoriais.

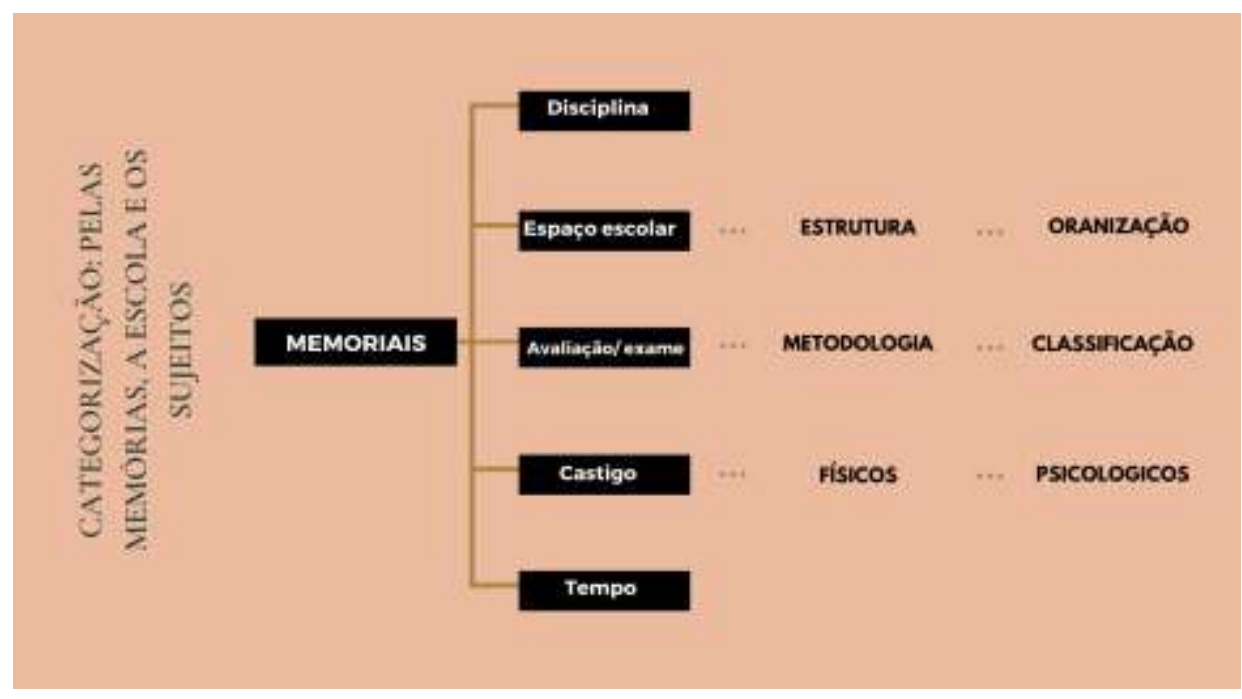

Fonte: Autores.

A Figura 2 indica uma representação de como se deu a organização das categorias e subcategorias. Para tal, foi criada uma tabela onde as citações extraídas dos memoriais eram colocadas, junto com o número da página e o nome do autor. As citações tiradas dos textos foram escolhidas a partir das categorias citadas anteriormente, desta forma foram sendo organizadas de acordo com suas categorias e subcategorias.

\section{Resultados}

\subsection{Caracterização dos sujeitos}

Foram analisadas 75 (setenta e cinco) memoriais, sendo utilizadas 4 (quatro) categorias para classificar os participantes que produziram os documentos. Sendo elas sexo, escola de rede pública ou rede privadas, idade e região urbana ou rural.

Os participantes foram divididos entres suas identidades de gênero, para que seja possivel obter uma melhor compreenção das situações que ocorreram mais frequentemente entre pessoas do mesmo sexo. Assim, podendo analisar também qual foi o público que mais aderiu ao projeto e a feitura da atividade proposta. Como podemos observar na Figura 3, logo abaixo:

Figura 3: Gráfico de gênero.

\section{Contagem de HOMEM/MULHER}

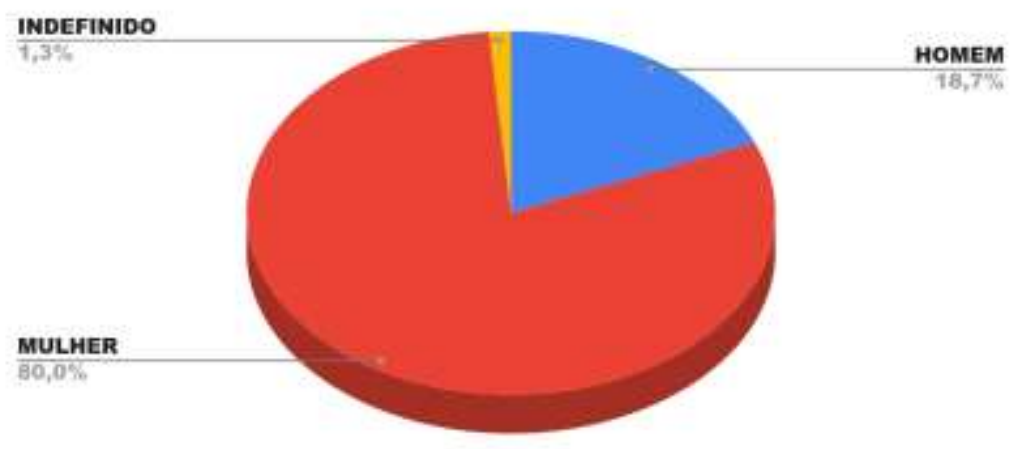

Fonte: Autores. 
Com os resultados podemos observar que cerca de $80 \%$ por cento do público do projeto foi composto de mulheres (Grupo M) e aproximadamente 18\% por cento foi composto por pessoas do sexo masculino (Grupo H). Como podemos observar no gráfico representado na Figura 3, o número de mulheres se sobressai de maneira bastante numerosa com relação ao sexo masculino. Desta forma, podemos concluir que grande parte das memórias a serem utilizadas contaram de um optica da vivência de mulheres dentro das escolas, memórias essas que tem uma visão diferente e percepção diferente.

É importante salientar que não foram usadas outras formas de denominações de gênero, pois como o material não foi feito relacionado diretamente para esta pesquisa não foi possível ser mais detalhista com relação a este ponto. Assim sendo escolhido apenas os gêneros feminino e masculino para a amostragem, visto que os gêneros nesta situação foram catalogados de acordo com os nomes dos participantes.

Para a próxima classificação denominada "Escolas da rede pública e Rede privada", foram distribuídos os participantes entre o tipo de ensino em que passaram a maior parte de sua vida escolar, sendo isto importante ressaltar, visto que a muitas pessoas que tiveram a experiência de passar pelos dois tipos de instituição. Sendo assim, foi levado em consideração o tipo em que foi passado mais anos pelos participantes.

Este critério de classificação foi criado com o intuito de relatar qual o tipo de ensino vivido pelos participantes, entendendo que as diferentes realidades entre o ensino público e privado no contexto brasileiro traz à tona uma grande disparidade entre eles. Portanto, as memórias poderiam variar entre as duas diferentes realidades entre os indivíduos, como também as situações vividas em cada espaço escolar. Dando ênfase principalmente aos espaços escolares, focados nas estruturas e organização das escolas.

Como vemos no gráfico da Figura 4, um pouco mais da metade dos alunos passaram a maior parte da vida escolar, se não toda ela, em uma escola pública (GRUPO RPU), mais especificamente 58,7\% (cinquenta e oito vírgula sete por cento). Já a escola particular (GRUPO RPA) contou com cerca de 36\% (trinta e seis por cento) de participantes que passaram toda sua vida escolar, ou a maior parte dela em uma escola particular.

Figura 4: Gráfico de escolas da rede pública e rede privada.

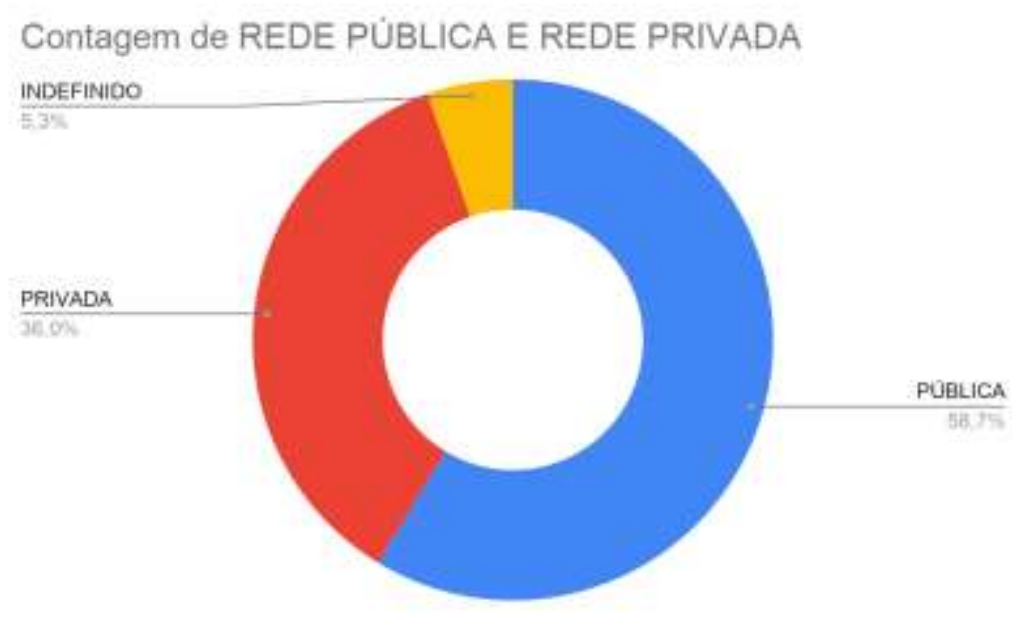

Fonte: Autores.

A idade foi o terceiro método de classificação utilizado para classificação dos participantes, visando a descoberta de uma média temporal onde cada um estudou. Sendo divididos entre aqueles que nasceram antes dos anos dois mil (GRUPO A) e aqueles que nasceram depois dos anos 2000 (GRUPO D). Utilizando esta marca temporal para separar os tipos de experiências vividas em séculos diferentes. 
É interessante considerar essa perspectiva temporal da escola, quando se é observado que muitas vezes há muitas semelhanças entres os memoriais. Quando se fala de perspectivas de gerações diferentes, esperasse que algumas situações presenciadas em âmbito escolar também sejam diferentes. E é a partir desta perspectiva que se deu a importância deste meio de classificação.

Pelo gráfico da Figura 5, podemos observar que boa parte dos participantes passaram a maior parte de sua vida escolar após os anos 2000. Chegando a um número de mais de 40 pessoas, que provavelmente estão na casa dos 20 aos 30 anos. Já há cerca de 30 participantes que percorreram a escola antes dos anos dois mil, ou seja, já estão acima dos 40 anos.

Figura 5: Gráfico de idade.

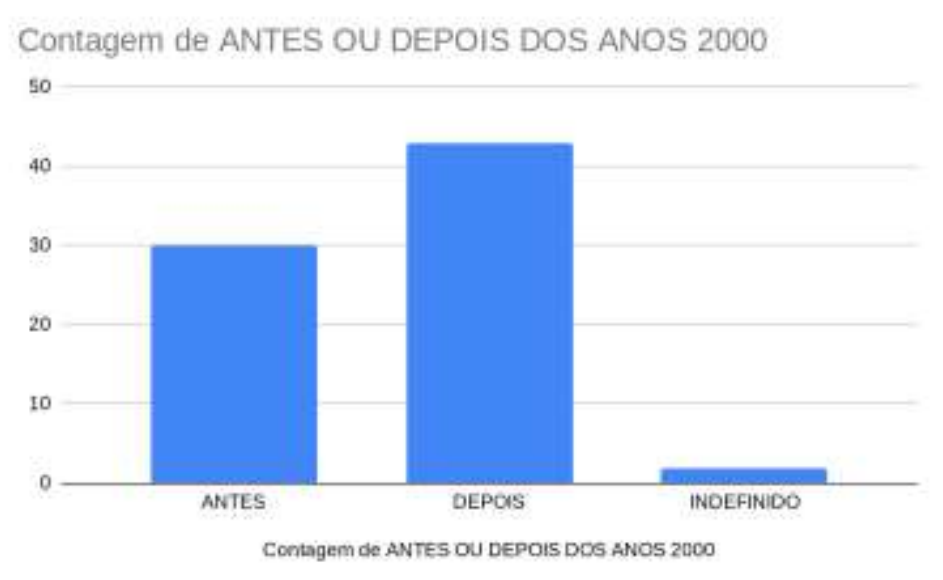

Fonte: Autores.

Por último, mas não menos importante, o quarto critério de classificação se deu pela contagem do alunado referentes aos locais onde as suas escolas se localizavam. Segmentando assim os alunos em dois grandes grupos, aqueles que passaram a maior parte de sua vida escolar em uma área urbana ou rural. Levando em consideração o local onde a escola se encontrava e não onde o estudante residia.

Este quesito de classificação foi escolhido levando em conta a busca das diferentes dinâmicas, vividas em dois espaços escolares totalmente distintos. Se essas diferenças realmente existem e quais são elas, levando em questão as questões estruturais e metodológicas. Informados na Figura 6, apresentado logo a baixo: 
Figura 6: Gráfico de espaço urbano e rural.

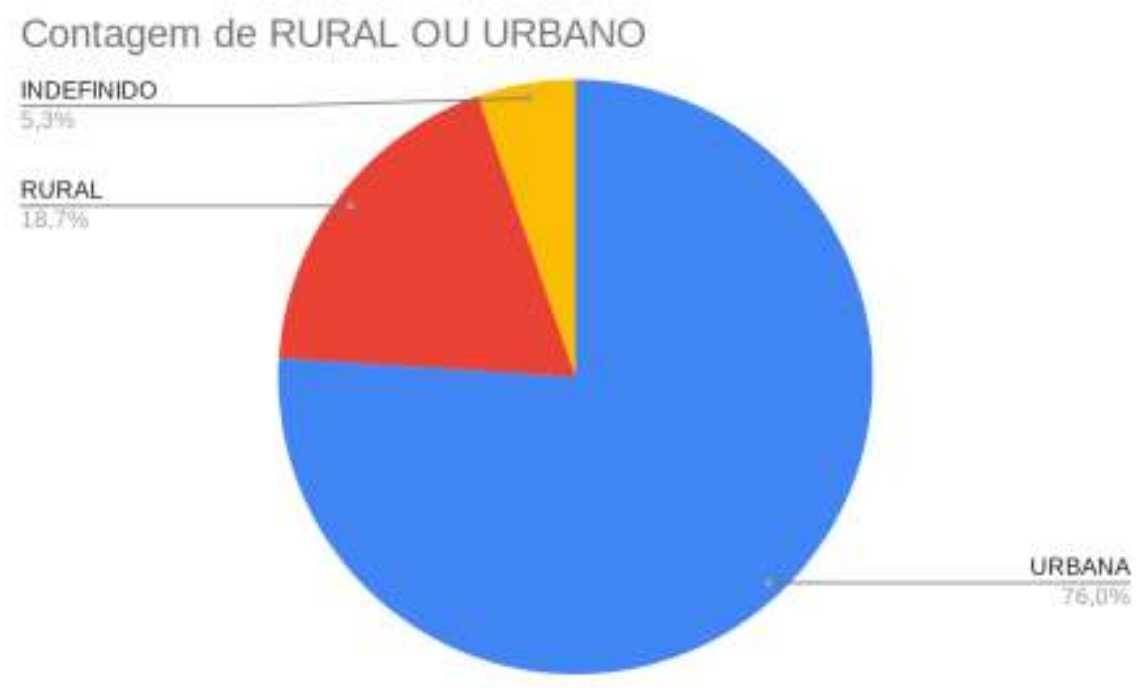

Fonte: Autores.

Assim, podemos analisar, a partir do gráfico retratado na Figura 6, algumas considerações. Uma maioria considerável realizou sua vida escolar em um espaço urbano (GRUPO U), contando cerca de 76\% do alunado analisado. Já o espaço rural (GRUPO R) contou com cerca de 18,5\% dos alunos, que passaram a maior parte de seus tempos na escola nesses espaços.

\section{Discussão}

\subsection{Tessituras teóricas: sociedade disciplinar, controle e memória}

No livro Sociedade do cansaço o autor Han Byung Chun, apresenta a seguinte afirmativa: "A sociedade do século XXI não é mais a sociedade disciplinar, mas uma sociedade de desempenho. Também seus habitantes não se chamam mais "sujeitos da obediência”, mas sujeitos de desempenho e produção.” (Han, 2015, p. 14). E apesar de em alguns pontos sua afirmação fazer sentido, visto que realmente vivemos em uma sociedade que se baseia em desempenho, não podemos afirmar que não se vive mais em uma sociedade do controle. Visto que esse desempenho e produção citados pelo autor partem de alguma máxima, que continua controlando e determinando como as pessoas devem se mostrar e viver.

Com a alta velocidade em que as transformações vêm acontecendo na humanidade nos últimos séculos, podemos presumir que novos modelos de sociedade e de se controlar essa sociedade vão sendo também transformadas. Desta forma, é válido dizer que vivemos sim atualmente na sociedade do desempenho, temos a todo momento tendo que provar a outros e a nós mesmos que estamos fazendo algo de útil. Porém, podemos definir esse desempenho como uma mais nova forma de controle que foi trazido principalmente com a inserção da mídia e redes sociais em nossa sociedade.

São reproduzidos pelos meios de comunicação estilos de vidas totalmente fora do padrão, que vão fazendo com que pessoas que não estão dentro daquele padrão buscarem chegar em um status que talvez seja impossível. E isso se aplica nas roupas da moda, poderes aquisitivos e até em níveis de conhecimentos. O que não percebemos é que esse desempenho também é uma forma de controle, o que mudou foi que ganhamos mais instituições que detêm esse poder. Poder esse que pode ser muito mais forte e se dissipar mais rápido hoje em dia, devido as grandes corporações que atuam por meio da mídia que nos lembram todos os dias qual a forma mais adequada que devemos viver as nossas vidas.

Partindo desta perspectiva, é que este trabalho pretende apresentar como a escola ainda no final do século XX e início do XXI ainda possui situações que uma instituição disciplinar e para isso se válida a partir principalmente dos pensamentos do 
autor Foucault (1987; 2003). Usando também de autores e de trabalhos que relacionam as relações de poder à dinâmica escolar, observando seus pontos mais importantes como argumentativos para apresentar as ideias que serão trabalhadas durante este trabalho. Correlacionando seus pensamentos as ideias tratadas no presente projeto.

Para a autora Áurea Guimarães, no livro A Dinâmica da Violência Escolar: Conflito e Ambiguidade, é a escola que transmite que ela "se diz democrática, mas não o é; diz que prepara para a vida, mas não o faz; é lugar do novo, mas propaga o velho." (Guimarães, 1996a, p. 25). Dando assim, a entender que mesmo com o passar dos séculos e a criação das mais variadas metodologias, a escola ainda não evoluiu em determinados aspectos. As dinâmicas escolares ainda circulam em sua maioria apoiadas em concepções da escola tradicional, que apresentam uma educação que apenas transmitem um conhecimento que não prepara os alunos para a vida. Partindo dessas poucas mudanças nas dinâmicas de funcionamentos dentro das escolas, entendesse que há uma motivação para tal.

E é sobre isso que é trazido no artigo intitulado Disciplina, controle social e educação escolar: Um breve estudo à luz do pensamento de Michel Foucault apresenta quando as autoras falam que "A escola, entendida como instituição disciplinar que "fabrica" indivíduos dóceis e úteis para o sistema capitalista, é uma das instituições que mais exercitam e mantêm o controle disciplinar." (Cruz; Freitas, 2011, p. 47).

Desta forma, podemos induzir a pensar que a escola objetiva manter seus alunos submissos aos conteúdos e visões de mundo limitadas pelos livros didáticos e filosofias escolares. Garantindo por meio disto, que o aluno seja moldado ao bel prazer do que é imposto pela sociedade atual que o cerca. E é a partir deste controle disciplinar que a escola age para controlar os alunos, não só eles mas, todos que trabalham dentro do contexto escolar. E serão estes tipos de situações de controles que serão analisadas nas memórias educativas que serão analisadas.

As situações de vivência escolar a serem analisadas, a partir da leitura dos memoriais trazem à tona o que Foucault denomina no livro Vigiar e Punir, por dispositivos de controle. Sendo eles o olhar hierárquico, a sanção normalizadora e o exame. Segundo o autor "O sucesso do poder disciplinar se deve sem dúvida ao uso de instrumentos simples: o olhar hierárquico, a sanção normalizadora e sua combinação num procedimento que lhe é específico, o exame.” (Foucault, 1987, p. 219).

Desta maneira, o autor apresenta esses dispositivos como uma forma disciplinar que de certa forma irão garantir a submissão do ser que está exposto aos mesmos. Podendo assim, relacioná-los à forma como a dinâmica escolar ainda funciona e quais as suas relações com os alunos que estão expostos a essa disciplina. Direcionando essas vivências disciplinares, por assim dizer, aos relatos dos memoriais analisados com o detrimento de se realizar um comparativo entre as situações.

O olhar hierárquico, parte do princípio de manter o máximo de indivíduos em ordem ao mesmo tempo, com o menor número de vigilantes possíveis. Partindo de uma organização que permita essa hierarquização e um bom exemplo disto é a sala de aula com sua organização. Em que consiste no professor em frente aos alunos, numa posição que permita observar todos que estão dentro da sala de aula, um lugar fechado.

Já a sanção normalizadora, pode ser explicada por meio das punições, em que essas penalidades podem ser também vistas em pequenas ações do dia a dia escolar. Embora pequenos, essas micro-penalidades fazem parte da formação dos indivíduos principalmente nas escolas. (Foucault, 2003). Esses castigos são gerados a partir do desenvolvimento dos ideais do que é o indivíduo perfeito para aquela instituição, na escola também conhecido como o "bom aluno". E para os alunos chegarem a o nível desejado, são aplicadas as sanções normalizadoras que vão desde um "sente direito, garoto" até um "você está suspenso por 3 dias".

Quanto ao exame, ele apresenta características de controle que permite que os indivíduos sejam qualificados, classificados e punidos, funcionando como um mecanismo que liga o saber ao poder. Permitindo assim, que os sujeitos possam se manter dentro de um nicho em que ele vai se sentir importante para aquele processo, mas está apenas dando continuidade ao processo. Considerando esses entendimentos sobre dispositivos é que os relatos dos participantes do projeto foram catalogados 
e selecionados.

Por tal, também considerou-se o pressuposto de que as memórias são um elemento de extrema importância para a realização deste trabalho. Baseado nisto, podemos trazer o conceito de memória apresentado por Le Goff, no livro História e Memória em que ele fala que "A memória, como propriedade de conservar certas informações, remete-nos em primeiro lugar a um conjunto de funções psíquicas, graças às quais o homem pode atualizar impressões ou informações passadas, ou que ele representa como passadas." (Le Goff, 1990, p. 266).

Esses conjuntos de funções psíquicas foram são importantes na construção de um memorial, pois são essas memórias que o compõe, levando sempre em conta que as memórias partem do ponto de vista dos participantes que as escreveram. Assim podemos afirmar, como fala Jane Quintiliano Guimarães Silva, em seu artigo sobre $O$ memorial no espaço da formação acadêmica: (re)construção do vivido e da identidade:

\begin{abstract}
Nesse raciocínio, o mundo representado não pode nunca ser idêntico, do ponto de vista espaço-temporal, ao mundo real, àquele que representa, àquele onde se encontra o autor que criou essa imagem. Em outros termos, fabrica-se discursivamente um mundo, cuja existência não resulta de meras reproduções de objetos do mundo objetivo (fatos, situações, figuras, pessoas, etc.), mas de um trabalho linguageiro que constrói uma realidade discursiva, fundada a partir do modo como o sujeito interpreta o "real" e significa-o no bojo de uma dada situação de interlocução. Daí reconhecer a pertinência de ditos populares como: "Quem conta um conto aumenta um ponto" ou "Quem conta aumenta, mas não inventa" (Silva, 2010, p. 606).
\end{abstract}

Desta forma, não devemos considerar todas as memórias como uma verdade absoluta, porém, é a verdade daquele indivíduo que a escreveu e essa é uma parte importante para este trabalho. Já que os autores dos memoriais relataram sobre suas vidas escolares partindo de seus pontos de vista das histórias e dos acontecimentos. É a visão do sujeito aluno e como ele observa todo o mundo escolar a sua volta, após anos de reflexão dentro e fora do curso de pedagogia.

A feitura de um memorial é relevante à formação, pois permite que os alunos, principalmente dentro da pedagogia, ressignifiquem as ações que foram vividas. Para que possam, ser usadas de exemplo por si mesmo na construção de um bom profissional da área, pois desta maneira todas as circunstâncias que o trouxeram até aí, vão ser usadas. Sejam elas de uma maneira positiva ou negativa.

\title{
4.2 Categorização: pelas memórias, a escola e os sujeitos
}

Para a categorização dos memoriais foi empreendida a análise de conteúdos, a partir da qual foram organizados fragmentos das memórias escolares nas categorias, previamente pensadas, a saber: disciplina, castigo, avaliação, espaço escolar e tempo.

\subsection{Disciplina}

Para esta categoria foi selecionada as citações que remetem a acontecimentos em que a disciplina foi de alguma forma utilizada. Levando em consideração que a disciplina foi usada de forma que levasse desconforto aos alunos, sendo relatados de tal forma. Podendo também encontrar pequenas situações do dia a dia que podem passar despercebidas pelos alunos, encaixandose no conceito de disciplina trazido por Michel Foucault, no livro A Ordem do Discurso, que o autor relata que "a disciplina é um princípio de controle da produção do discurso. Ela lhe fixa os limites pelo jogo de uma identidade que tem a forma de uma reatualização permanente das regras" (Foucault, 2012, p. 36).

Portanto, podemos concluir que a disciplina é um instrumento de dominação, que tem como objetivo de docilizar as ações divergentes às ideias centrais que são pregadas pelas instâncias maiores. Trazidas pelo Estado como uma forma de controle, centralizando este poder no que Foucault chama de "Instituições disciplinares". Instituições essas que são formadas por prisões, 
hospitais, igrejas e o foco principal deste trabalho, as escolas.

Partindo destas proposições sobre disciplinas que as memórias foram selecionadas, dentre os 75 memoriais analisados, 10 citações que de alguma forma apresentam este uso do poder disciplinar foram selecionadas. Essas memórias constam de situações, em que de alguma forma os alunos deveriam seguir uma certa conduta que lhe era esperada. E para que isto fosse possível ser feito, recebiam de alguma forma ameaças para quando este código de conduta não fosse seguido. Como podemos ver a seguir em alguns dos relatos selecionados:

Memória 1: "me recordo do "quartinho escuro" que era uma sala de depósito mas que as professoras usavam como justificativa para colocar medo nos alunos que não estivessem tendo um bom comportamento e também tinha a cadeirinha do castigo" (Participante A.N).

Memória 2: "Quando a turma se comportava mal, bastava a professora olhar de forma compenetrada para os alunos. Ela não dizia uma palavra. Todos se calavam." (Participante H.A).

Nestas memórias de duas participantes, podemos ver que elas remetem à professora e ao uso de um artifício que causa medo aos alunos. No primeiro caso em específico, o que a participante A.N, pertencente aos grupos (M; RPU; A; R) chama de "quartinho escuro", consistia em um objeto disciplinador, pois apesar de ser só para causar "medo", a ameaça ainda estava presente como uma forma de fazer com que os alunos se comportarem da maneira que, era desejada pela professora e pela instituição escolar.

Já no segundo relato do participante H.A, pertencente aos grupos (H; A; RPU; U) a professora nem se valia de uma moeda de troca para causar medo aos alunos. Apenas o seu olhar e sua expressão eram capazes de fazer com que todos os alunos se calassem e se comportassem, em uma ameaça silenciosa, porém, eficaz. Essa situação em específico, nos mostra que o controle pode ser exercido não apenas com ações físicas, mas também nesta vigilância velada exercida por muitos professores.

Para isso Foucault, traz no livro A verdade e as formas jurídicas o seguinte conceito de vigilância

Não se trata de reconstruir um acontecimento, mas de algo, ou antes, de alguém que se deve vigiar sem interrupção e totalmente. Vigilância permanente sobre os indivíduos por alguém que exerce sobre eles um poder --- mestre-escola, chefe de oficina, médico psiquiatra, diretor de prisão --- e que, enquanto exerce esse poder, tem a possibilidade tanto de vigiar quanto de constituir, sobre aqueles que vigia, a respeito deles, um saber. (Foucault,, 2003, p. 88).

Como citado acima, o professor tem o poder da vigilância dentro da instituição escolar, chegando ao ponto em que as punições não precisam ser aplicadas. Visto que apenas pela vigilância e ameaça pode trazer o sentimento de medo aos alunos, ou seja, sendo usados como uma espécie de controle de danos. Já que desta maneira se consegue o objetivo inicial de manter a sala de aula dentro dos padrões exercidos, em completo silêncio e "prestando atenção na aula".

Nos relatos a seguir (Memórias 3 e 4) podemos observar como a disciplina também se aplicava ao engessamento dos corpos, por meio de regras de vestimentas. Visto que, até para a forma em que os alunos se vestiam deviam estar rigorosamente alinhados aos pensamentos e regimentos da escola. As questões de vestimentas foram um dos assuntos mais descritos dentro de todos os memoriais.

Memória 3: "Uniforme completo com camisa e short saia para as meninas, tênis preto ou branco e meia branca" (Participante L.C).

Memória 4: "Roupas sempre limpas, meias brancas, tênis azul ou branco, calça azul e fardamento impecável. Não podíamos usar batom, os meninos tinham que manter o cabelo com corte tipo soldado." (Participante M.D). 
Nessas situações podemos ver o que Foucault chama de "o bom adestramento", o sujeito não faz parte de sociedade de forma individual, mas sim é parte de uma engrenagem dentro da instituição. Desta forma, o sujeito não possui mais uma personalidade única, agora ele faz parte de todo um sistema em que se deve estar dentro de um padrão estipulado, assim incluindo a uniformização da vestimenta. Desta maneira facilita a dominação desses alunos, mantendo todos no mesmo patamar. Como podemos observar nas memórias trazidas nos relatos número 3 e 4 , em que os participantes pertencem respectivamente aos grupos (M; D; RPA; U) e (M; A; RPA; U) que mesmo em épocas distintas, o mesmo padrão de exigência com relação a vestimenta e padronização são bastantes comuns. E que isto é usado como uma forma de padronização e dominação dos alunos. Desta maneira, podemos concluir que a disciplina é um instrumento de dominação, que possui como principal objetivo a docilização dos corpos. Assim os ideais e ações divergentes e se opuseram aos das instâncias maiores, conseguem ser controlados e moldados. Usando de artifícios e instituições que deveriam dispor da libertação desses indivíduos, proporcionou um novo pensamento em vez de do engessamento em um sistema antigo e falido.

\subsection{Castigo}

Para a categorização de castigo, foram escolhidas aquelas situações em que os alunos relataram punições ou até mesmo repreensões, feitas principalmente pelos professores ou funcionários da escola, que desencadearam em algum exagero por parte deles. Essa categoria foi dividida em duas subcategorias: castigos físicos e castigos psicológicos para que houvesse uma melhor organização. Nestes termos, acrescenta Foucault (1987, p. 171-172):

Na oficina, na escola, no exército funciona como repressora toda uma micro penalidade do tempo (atrasos, ausências, interrupções das tarefas), da atividade (desatenção, negligência, falta de zelo), da maneira de ser (grosseria, desobediência), dos discursos (tagarelice, insolência), do corpo (atitudes 'incorretas', gestos não conformes, sujeira), da sexualidade (imodéstia, indecência). Ao mesmo tempo é utilizada, a título de punição, toda uma série de processos sutis, que vão do castigo físico leve a privações ligeiras e a pequenas humilhações.

Partindo dessa afirmação podemos constatar que as punições analisadas, partem desses "processos sutis" de castigos. Assim, considera-se que os castigos físicos não só constaram de ocasiões em que ocorreu violência física, mas ainda, em atos que foram considerados errados e foram punidos com trabalho manual. Já os castigos psicológicos, se focaram principalmente na ocorrência de situações degradantes e humilhantes para com os alunos. Partindo desta perspectiva, foram coletadas cerca de 13 situações em que o castigo esteve presente, dentre dezenas que foram encontrados dentro dos memoriais.

Quando tratamos do castigo dentro das instituições de controle, falamos sobre o controle punitivo ou naquilo que Foucault apresenta no livro A Ordem do Discurso, quando trata da "polícia para a vigilância, as instituições psicológicas, criminológicas, médicas, pedagógicas para a correção". (Foucault, 2012, p.86).

Neste sentido, os castigos escolares são considerados o meio da escola de aplicar a correção ao aluno, por um ato ou opinião que foi de contra o que se é esperado dentro da instituição. Como podemos observar nas memórias 5 e 6 , que serão mostradas a seguir, em que os participantes do projeto sofreram algum tipo de punição sobre algo.

Memória 5: "Esse símbolo do autoritarismo e da disciplina estavam ali presentes e constantemente lembrados pela Professora Ana ou pela diretora, sempre em tom de ameaça: oh, quem fizer bagunça ou má criação leva "bolo" na mão. Mesmo não sendo utilizada, a sua existência nos fazia meninos e meninas contidos" (Participante R.C).

Memória 6: Certa feita, escrevi "cilêncio" e a professora ficou brava: passei o recreio, forma como se chamava o intervalo, todinho escrevendo a palavra de forma correta - 100 vezes a palavra "silêncio" (Participante A.M).

As memórias 5 e 6 foram escolhidas como representações, da forma em que os castigos físicos ainda se encontram 
presentes nas escolas. No caso da memória número 5, que pertence a um participante dos grupos (M; A; RPA), que retrata o famoso "bolo", também conhecido como o uso da palmatória. ${ }^{7}$ Castigo bem famoso e que apesar de ter sido abolido definitivamente com a criação do Estatuto da Criança e do Adolescente, em 1990, ainda podem ser encontrados em memórias escolares de alunos que passaram pela escola após esse ano, como é o caso da Participante R.C, memória 5.

Já na memória número 6, em que o participante pertence aos grupos (M; A; RPA; U), podemos ver o castigo físico, mas não de uma forma que causa dor ou machucados. Mas sim, em um castigo que resulta em uma ação punitiva, onde como no exemplo a aluna teve que escrever a mesma palavra 100 vezes, isso apenas por ter escrito uma letra errada em toda a palavra. Castigos como esse são mais comuns em algumas escolas até nos dias atuais, percebendo que algumas ações ainda insistem em permanecer iguais.

Quanto aos castigos psicológicos, como os apresentados nas memórias 7 e 8, apresentadas logo abaixo, estamos abordando da forma punitiva de castigo que mais se instaura atualmente. Em virtude de que, os castigos físicos são proibidos em todas as instâncias na maioria dos países do mundo. Portanto, agora são mais comuns situações como as vistas em seguida.

Memória 7: "Lembro de ter sofrido bullying nesta escola, pois um dia adormeci na sala e a professora parou a aula para todos olharem para mim, até que eu acordasse." (Participante A.O).

Memória 8: "No dia seguinte, levei o cartaz e lembro da sensação de constrangimento em relação ao meu trabalho comparado aos demais, que tinham ficado bem mais bonitos. A professora colou os cartazes nas paredes da sala de aula e, no dia seguinte, encontrei apenas o meu trabalho no lixo." (Participante A.O).

As situações postas nas memórias 7 e 8 são compostas por pequenas humilhações que foram causadas dentro do âmbito escolar, partidos de educadores que estavam em sala de aula. Esses tipos de ocorrências sendo acometidas a crianças, apenas por dormir em sala de aula, como na memória número 7, ao qual o participante está (M; D; RPU; U) nos grupos ou por ter o trabalho sido jogado fora como a memória 8, que também pertence ao grupo (M; D; RPU; U) são os motivos para uma possível descrença na importância da educação ou pior em si mesma. Depreendemos que são essas sutis situações que podem fazer o aluno se sentir reprimido em sala de aula.

E essa é a intenção da punição, fazer com que os sujeitos punidos reprimam seus atos e comportamentos. Por exemplo: se a Participante A.O. tivesse feito um trabalho dentro dos parâmetros que provavelmente foram estipulados, dentro do padrão concebido pela professora essa situação não teria acontecido. Sempre partindo assim, da idealização de uma adequação que não é inerente a todos que pertencem àquele contexto escolar, em que os alunos devem chegar a um ideal que não é comum a todos.

\subsection{Avaliação}

Na categoria "avaliação" foram selecionadas memórias que estão ligadas às situações em que os processos avaliativos afetaram os participantes de alguma forma. Indo além, de processos avaliativos, algumas memórias também relatam como se dava o dia a dia na escola com relação aos conteúdos. E pela forma em que os professores trabalham esses conteúdos.

A partir disso, foi necessário dividir essa categoria em duas subcategorias que foram denominadas "metodologia" e "classificação". Sendo a primeira mais focada nas abordagens metodológicas, partido dos professores e da escola. Já na segunda, consta as situações onde os alunos eram de alguma forma classificados ou premiados dentro das instituições escolares. Ao final contando com 22 citações, retiradas dos 75 memoriais lidos.

Levando essas informações em consideração, podemos observar nas memórias 9,10 e 11, como os estudantes

\footnotetext{
${ }^{7}$ A palmatória conta de um bastão de madeira que foi introduzido pelos jesuítas, na época de colonização do Brasil. Como uma forma de punição aos indegenas que se mostravam contrários aos seus ensinamentos, sendo perparssado depois para o uso durante a escravidão africana. Posteriormente sendo usado como forma de castigo nas escolas.
} 
enxergavam as atividades que eles faziam. Sendo em sua totalidade, baseadas em atividades completamente tradicionais e que não se importavam com o contexto em que seria tratado. Marcado por uma sequência de escrita e leituras que não levariam a lugar nenhum e não faziam sentido. Como podemos observar abaixo:

Memória 9: "Os professores, na maioria das vezes, trabalhavam a metodologia da repetição e dos exercícios de fixação, seguido das provas que tinham como finalidade apenas avaliar o grau de decoreba dos alunos." (Participante H.M).

Memória 10: "Entre as atividades, a cópia de textos figura entre as mais requisitadas, ao ponto de me deixar calos nos dedos e muito cansada." (Participante A.G).

Memória 11: "Minha alfabetização se deu de maneira muito comum com ditados, copiar o próprio nome várias vezes, juntar sílabas e copiar textos, confesso que copiar não era muito a coisa que eu mais gostava de fazer, escrevia com um pouco de raiva, nada disso fazia sentido para mim [...]” (Participante A.G).

Fica claro nas afirmações aquilo que Paulo Freire traz no livro Pedagogia do Oprimido e, denominou de educação bancária, ao expressar que:

A narração, de que o educador é o sujeito, conduz os educandos à memorização mecânica do conteúdo narrado. Mais ainda, a narração os transforma em vasilhas, em recipientes a serem enchidos pelo educador. Quanto mais vá enchendo os recipientes com seus depósitos, tanto melhor educador será. Quanto mais se deixem docilmente encher, tanto melhores educandos serão. Desta maneira, a educação se torna um ato de depositar, em que os educandos são os depositários e o educador o depositante. (Freire, 1987, p. 37).

Partido da citação de Freire, podemos observar o que ele chama de ${ }^{8}$ educação bancária, para compreender as memórias 9, 10 e 11, em que os alunos participam respectivamente dos grupos (M - A - RPU - U; M - D - RPU - U e M - D - RPU - U). Em que os alunos possuem apenas o papel de passividade dentro de sala de aula, somente absorvendo os conteúdos que lhe são impostos, sem estabelecer uma reflexão ou o mínimo de análise sobre o que está sendo absorvido, tornando-se assim, apenas um mero depósito de conteúdos. Para que as metas internas de aplicação das matérias sejam atingidas, pouco se importando até se o alunos realmente aprendeu algo.

Essa prática pode ser caracterizada por alguns dos elementos trazidos nessas memórias, encontradas nas práticas mais tradicionais de ensino. Como os exercícios de repetição trazidos na memória nove, a cópia de textos como na memória 10 e o método de juntar sílabas para aprender a escrever trazido na memória 11. Todos esses elementos citados, fazem parte de uma prática tradicional de ensino, se aplicadas sem nenhum contexto e unicamente.

Relacionado a isto, agora partimos para as memórias referentes à subcategoria de "classificação". Mostrando duas situações específicas em que as escolas dos participantes se importavam bastante com o posições, seja entre os alunos e até da pŕopria escola. Como podemos ver nas memórias número 12 e 13, apresentadas logo abaixo:

Memória 12: "No final do ano letivo, era colocado um mural na escola com as fotos dos melhores alunos da escola, chamado de "As melhores cabeças", que tiveram a média anual acima de 80 em todas as disciplinas, então fui um dos destaques durante o ano." (Participante D.F).

Memória 13: "Apesar de ter tido uma rotina muito puxada e desnecessária no último ano, situação comum em escolas particulares que querem poder ter um índice de aprovação no ENEM maior para poderem atrair mais alunos, fazendo com que o ensino médio seja completamente focado em tirar uma boa nota na prova [...]” (Participante I.C).

\footnotetext{
8 Termo trazido por Paulo Freire, que significa que os alunos são vistos apenas como um banco, em que o professor apenas deposita todo o seu conhecimento.
} 
Por meio dessas memórias podemos constatar uma prática que apesar de bem antiga, ainda vem sendo utilizada nas escolas como forma de "incentivo" aos alunos. Como podemos ver na memória 12, cujo a participante pertence aos grupos (M D - RPU - U) em que a escola simplesmente separava "as melhores cabeças" da escola, com todos aqueles que tinham uma nota acima da meta que era imposta pela escola. A denominação de "melhores cabeças", por si só, já é muito emblemático e problemático visto que dá a entender que essas cabeças são mais avançadas e evoluídas do que as outras.

Ou seja, apenas por uma nota acima de 80 pontos, determina quem são os melhores e os piores dentro da escola. Esse tipo de prática a um longo prazo pode trazer vŕias implicações e dúvidas para esses alunos que são classificados como meros objetos. Aqueles que estão acima da média, irão sempre se cobrar mais e mais para continuar no "topo", e aqueles que não estão no topo começarão a tentar alcançar metas inalcançáveis. Entrando assim num ciclo sem fim de tentativas e frustrações, visto que sempre haverá um novo padrão e uma nova meta a ser seguida.

Já na segunda memória, que é de uma participante que está dentro dos grupos (M-D-RPA-U), podemos ver que não apenas os alunos entram nessa busca infinita pela perfeição e atingimento de metas, pois a partir de um determinado ponto na história, a luta passou a ser também entre as escolas. Podemos entender isso melhor quando observamos atualmente, o quanto a escola virou um mercado de aprovações no Exame Nacional do Ensino Médio (ENEM). Visto que o novo padrão de "boa escola" é o alto índice de aprovação neste exame, atraindo cada vez mais alunos para escolas que trabalham seus alunos feitos robôs prontos para entrar na corrida das notas perfeitas.

Podemos entender melhor esse "fenômeno" que vem acontecendo nas escolas com a fala de Foucault no livro A verdade e as formas jurídicas quando ele relaciona a escola com o poder judiciário e diz "O poder escolar é também inteiramente baseado em uma espécie de poder judiciário. A todo momento se pune e se recompensa, se avalia, se classifica, se diz quem é o melhor, quem é o pior." (Foucault, 2003, p. 120). Este poder que a escola assume, faz com que suas práticas e ideologias partam para a utilização de metodologias de compensação, como as de classificar os melhores alunos que ainda sejam usados e valorizados.

\subsection{Espaço escolar}

Nesta categoria foram compiladas citações referentes às lembranças dos alunos no espaço escolar em que os mesmos estudavam, contado com o espaço físico e a forma em que a escola se organizava. Por este motivo, esta categoria foi dividida em duas subcategorias: "estrutura escolar" e "organização". Esta primeira partindo para o conjunto de memórias sobre a estruturas físicas das escolas, como número de salas, o tamanho da escola e afins. Já a segunda conta com relatos sobre situações em que dá pra perceber a forma que a escola se organiza, durante algum acontecimento.

Sobre tal, ressalta-se o entendimento de Michel Foucault no livro A verdade e as formas jurídicas, quando o autor apresenta a ideia de Panopticon de Bentham, quando escreve a seguinte frase "Ele estava se referindo ao problema de uma arquitetura não mais do espetáculo, como a grega, mas de uma arquitetura da vigilância, que permite a um único olhar percorrer o maior número de rostos, de corpos, de atitudes, o maior número de celas possíveis" (Foucault, 2003, p. 106).

Neste trecho, o autor relaciona o quanto as instituições de controle, incluindo a escola, transformaram suas estruturas com o intuito de exercer a vigilância dos indivíduos. Desta forma, um único olhar, que seria o professor, pudesse dar conta de vigiar o maior número de corpos possíveis, os alunos. E para que os alunos estivessem sempre a vista de seu "vigia", a sala devia ter uma disposição que facilitasse isto, assim os professores se encontravam à frente da turma e os alunos, sentados enfileirados em suas carteiras. De modo que ao ficar em pé o professor tivesse uma ampla visão de tudo o que acontece em todo o espaço de sala de aula. Já dentro das citações selecionadas, partidas dos memoriais, a grande maioria se refere às instalações das escolas. Como podemos observar nas memórias número 14, 15 e 16, apresentadas abaixo: 
Memória 14: Também recordo que a sala de aula ser pequena, um pouco escura, com cadeiras duplas em madeira e no alto da parede no vão central para todos verem, havia um crucifixo e uma palmatória. (Participante R.C).

Memória 15: "O corredor da diretoria era um espaço "sagrado" nenhum aluno devia passar por lá, mesmo sendo uma criança já compreende que a ordem e a disciplina construíam os arquétipos desses tempos escolares, um modelo enrijecido." (Participante J.F).

Memória 16: "A Casinha Prática era uma réplica de casa para as alunas do ensino médio treinarem o seu aprendizado nas prendas domésticas, a Cozinha Prática - dividida em boxes equipados com fogões e utensílios de cozinha necessários a confecção dos pratos; a sala de costura - na qual eram ministradas aulas de crochê, bordado, costura e demais atividades manuais" (Participante A.M).

Na memória número 14, em que a participante pertence aos grupos (M-A-RPA), podemos ver o funcionamento organizacional do interior de uma sala de aula, em uma escola específica. Esta que possuía como destaque dentro da sala o crucifixo e uma palmatória, como possíveis símbolos da moral e dos bons costumes que deveriam ser oferecidos pela escola. Porém, estes objetos podem também ser vistos com os símbolos disciplinares para manter os alunos na linha e comportados como se almejava pela escola. A cruz como um símbolo religioso, retornará sempre aos alunos os preceitos que devem ser seguidos, já a palmatória os lembrará qual o seu destino se esses preceitos não forem seguidos.

Já na memória número 15, o relato foi feito por uma pessoa dos grupos (M-D-RPA-U) trouxe uma percepção de significação dos espaços escolares para os alunos, como a participante fala do lugar "sagrado" de sua escola. O simples fato de estar no corredor dos seus "superiores" dentro da instituição era motivo de medo dentro desta escola, pois era um lugar proibido. Partindo desta perspectiva, qual seria o diálogo dos alunos com a coordenação escolar se eles não podiam ao menos chegar perto de onde a coordenação se encontrava. A própria participante relata sentir a instituição enrijecida, onde a ordem e a disciplina prevalecem.

A memória 16, traz uma perspectiva de uma participante dos grupos (M-A-RPA-U), que estudou em uma escola onde além dos conteúdos básicos, também se ensinava os princípios básicos de atividades domésticas e de como ser uma boa mulher e esposa. Assim, como ela diz em sua citação, em sua escola existia uma sala em que era possível simular uma casa, com sala e cozinha para que as meninas pudessem aprender os afazeres domésticos como uma boa dona de casa. Esse espaço demonstra uma visão de como essa escola enxerga as mulheres, os seus direitos e deveres perante a sociedade, ou seja, ao preparar as alunas que lá estudavam apenas para serem boas mulheres, como a passar roupas, cozinhar e costurar, atividades que as mulheres poderiam e deveriam fazer.

Quanto às questões organizacionais dos espaços escolares, foi extraído uma memória em específico que mais chamou atenção, apresentada na memória 17, de um participante dos grupos (H-D-RPA-U) logo abaixo:

Memória 17: "Na ausência do nosso professor titular, quem comandava o quadro negro era o então vigilante da escola." (Participante J.P).

Nessas memórias podemos ver um pouco de como as estruturas dos espaços escolares influenciam nas vivências escolares, e mostram que a forma em que esses espaços estão divididos demonstram muito sobre o funcionamento escolar. Em que os espaços trazem significados e ficam marcados na mente dos que permeiam aquele local, seja de maneira boa ou nem tanto, como podemos ver na memória 15 , mais especificamente.

Esta memória nos traz à tona a importância e o valor que o professor daquela escola possui, visto que sua ausência foi facilmente substituída pelo vigilante da escola. Este fato nos faz repensar o papel desse professor em sala de aula, se é de um educador ou de um mero repassador de conhecimentos. Já que sua ausência pode ser sanada por uma pessoa sem o mínimo de preparo acadêmico possível, para estar em uma sala de aula. Presume-se então que o único papel que o vigilante poderá ter na 
turma é fazer com que os alunos permaneçam comportados, e seguindo as ordens que devem ser seguidas.

Então, a partir deste relato podemos concluir que o papel do professor, também pode ser observado como um indício de controle da escola, pois, como ressalta Rusen (2011), é possível encontrar sentidos nas experiências temporais por meio de reflexões e dos estudos da História.

\subsection{Tempo}

Esta categoria denominada Tempo ${ }^{9}$ registrou memórias referentes aos momentos e situações referente a rotina escolar dos participantes. Partindo da premissa de que, o tempo é um conceito importante dentro do ambiente escolar, pois garante a organização e facilita o andamento das aulas, esta categoria possui as memórias relacionadas ao tempo, partindo principalmente dos momentos em que se percebeu uma forma de organização do dia a dia escolar. Como podemos observar nas memórias 18 e 19:

Memória 18: "Lembro que todos os dias, antes das aulas começarem, reuniam todas as turmas do ensino fundamental I no corredor das salas, e tínhamos que cantar músicas infantis, católicas e fazer orações antes do início das aulas". (Participante D.F).

Memória 19: "Tinha uma capela onde semanalmente éramos levados para assistir a uma missa e toda quinta feira, antes de começar a aula, tínhamos que cantar o hino nacional." (Participante A.G).

Nestas memórias podemos ver duas perspectivas de rotinas escolares dos participantes, que pertencem em sequência aos seguintes grupos (M-A-RPU) e (M-D- RPU-U). Ao observar esses relatos, podemos perceber que as partes mais marcantes da rotina das alunas são os rituais iniciais de suas escolas, em que neste caso estão fortemente ligados a questões religiosas e de saudação à pátria. Esses foram apenas dois dos vários relatos parecidos, em que a rotina dos alunos passaram pelos mesmos processos.

Para Foucault (1987, p. 137) a rotina dentro das instituições de controle, "trata-se de constituir um tempo integralmente útil". Ou seja, os alunos no caso das escolas não podem passar um tempo, considerado inútil para a instituição. Assim, todos devem estar sempre realizando alguma ação, ou produzindo algo de bom.

No caso dos relatos encontrados nas memórias número 18 e 19, utilizava-se do tempo escolar educacional, para dar continuidade a tradições ligadas à religiosidade e à pátria. Como uma forma de ocupar o tempo dos alunos, com algo que para aquelas instituições é importante, para que fosse possível manter o controle dentro da escola, usando dos pontos já tratados.

Por tais análises, consideramos, assim como Vidal e Silva (2020), o entrelaçamento da história, da história da educação e da memória é constituir um olhar atento às disputas, emoções, tensões e negociações que estiveram (e permanecem) envolvidas no (interminável) exercício de conferir significados ao passado educacional.

\section{Conclusão}

O presente trabalho de pesquisa, teve como tema a escola como instituição de controle, a partir de memórias escolares. Consequentemente, abordamos a maneira em que os chamados dispositivos de controle, abordados por Michel Foucault podem estar dentro das vivências escolares, mesmo após décadas em que foram escritas pelo autor. Usando de memórias educativas reais vividas por pessoas de diferentes idades, classes sociais e contextos.

A partir disto, podemos concluir, que dentro do processo formativo as memórias podem ser uma ferramenta formativa. Visto que, elas nos ajudam a construir um maior repertório de experiências e que mesmo sendo uma capacidade muito particular

${ }_{9}^{9}$ Para discussões teóricas sobre tempo e história, ver Chartier (2010). 
do ser humano, seu compartilhamento pode servir de grande aprendizado. Concomitantemente, o uso dessas memórias quando usados dentro de memoriais escolares, como os analisados neste trabalho. Podem se tornar objeto de estudos de um diverso leque de temas e abordar uma vasta gama de reflexões, pois, se trata de experiências verdadeiramente vividas.

Com relação a conexão entre os conceitos de memória, controle e escola, podemos observar ao decorrer do trabalho o quanto as ações e acontecimentos vividos dentro das escolas influenciam nos seres que estão sendo formados por aquela escola. As lembranças vivenciadas pelos participantes ficaram guardadas nas suas memórias e influenciaram suas visões referentes à escola e suas relações dentro dela. O que nos faz afirmar que as ações dos profissionais envolvidos dentre da área da educação ou que influenciam nas escolas, devem ser mais cautelosos com relação às suas condutas, pois elas estão diretamente envolvidas com a vida de seus alunos.

Em conclusão, as memórias colaboraram para que esta análise fosse concluída, chegando à conclusão de que apesar do passar de anos ainda podemos observar a escola como uma instituição de controle. Porém, não da mesma maneira absurdamente engessada como era na época em que Foucault escreveu sobre isso, mas sim uma versão repaginada e envolta nas novas formativas de controles em que nossa sociedade é cercada. Podemos sim, hoje, ser a sociedade do desempenho, mas esse desempenho que é nós cobrado pode ser visto como apenas mais um dispositivo de controle que vivenciamos.

\section{Referências}

Cruz, P. A. S. \& Freitas, S. A. de. (2011). Disciplina, Controle Social e Educação Escolar: um breve estudo à luz do pensamento de Michel Foucault. Revista Levs, (7), 36-49. ISSN 1983-2192. http://www.levs.marilia.unesp.br/revistalevs/edicao7/autores/3_DisciplinaControleSocialEducacaoEscolar.pdf“

Foucault, M. (2003). A Verdade e as Formas Jurídicas. 3. ed. Trad. Roberto Cabral de Melo Machado e Eduardo Jardim Moraes. Nau Editora

Foucault, M. (2012). A ordem do discurso: aula inaugural no Collège de France, pronunciada em 2 de dezembro de 1970. Tradução de Laura Fraga de Almeida Sampaio. Edições Loyola.

Foucault, M. (1987). Vigiar e Punir: história da violência nas prisões. Editora Vozes.

Guimarães, Á. M. (1996). A dinâmica da violência escolar: Conflito e ambigüidade. Autores Associados.

Certeau, Michel de Certeau (2014). A Invenção do cotidiano: artes de fazer. Tradução Ephraim Ferreira Alves. Petrópolis: Vozes.

Chacon, D. F., Sales Neto, F. F., \& Sales, D. S. C. (2020). Entre reflexões e fazeres: a construção do saber histórico escolar a partir do uso de reflexórios. History of Education in Latin America - HistELA, 3, e23445. https://doi.org/10.21680/2596-0113.2020v3n0ID23445

Chartier, Roger (2010). A história ou a leitura do tempo. Tradução Cristina Antunes. Belo Horizonte: Autêntica.

Freire, Paulo. (1987). Pedagogia do Oprimido. São Paulo: Paz e Terra.

Han, Chul Han. (2015). Sociedade do cansaço. Tradução de Enio Paulo Giachini. Petrópolis, Rio de Janeiro: Vozes.

LAHMED. Rio Grande do Norte: Ufrn. (2020). P\&B. https://www.youtube.com/c/LAHMEDUFRN/about.

Le Goff, Jacques. (1990). História e memória. Tradução Bernardo Leitão ... [et al.] -- Campinas, SP Editora da UNICAMP. (Coleção Repertórios).

Minayo, Maria Cecília de Souza. (1992). O desafio do conhecimento: pesquisa qualitativa em saúde. 6. ed. São Paulo- Rio de Janeiro: Hucitec-Abrasco.

Passeggi, M. da C. B. S. (2011). A experiência em formação. Educação, 34(2). https://revistaseletronicas.pucrs.br/index.php/faced/article/view/8697

Rusen, Jorn (2011). Jorn Rusen e o ensino de história. Curitiba: Ed. UFPR.

Sales, Antonia de Jesus. (2021). A escola através dos tempos. https://meuartigo.brasilescola.uol.com.br/educacao/a-escola-atraves-dos-tempos.htm.

Schueler, Paulo. O que é uma pandemia. (2021). https://www.bio.fiocruz.br/index.php/br/noticias/1763-o-que-e-uma-pandemia.

Silva, J. Q. G. (2010). O memorial no espaço da formação acadêmica:(re) construção do vivido e da identidade. Perspectiva, $28(2)$, 601-624. http://dx.doi.org/10.5007/2175-795x.2010v28n2p601.

Unicef. (2018). BTS speech at the United Nations | UNICEF. Estados Unidos: Unicef, 2018. P\&B. https://www.youtube.com/watch?v=oTe4f-bBEKg.

Vidal, D., \& Silva, J. C. S. (2020). Interpreters of the past and of the present: the art of historians of education and archivists. History of Education in Latin America-HistELA, 3, e20951-e20951. 